\title{
POTENSI EKSTRAK ETANOL DAUN ANDONG MERAH (Cordyline fruticosa (L.) A. Cheval) SEBAGAI ANTIOKSIDAN PENANGKAL RADIKAL DPPH
}

\author{
Yuri Pratiwi Utami ${ }^{1}$ \\ ${ }^{1}$ Bagian Biologi Farmasi, Sekolah Tinggi Ilmu Farmasi Makassar, Makassar \\ Email : yuriutami88@gmail.com
}

\begin{abstract}
Andong leaf is one of the traditional medicinal plants that is proven to have various properties including as a (natural) medicinal ingredient. Andong plants contain several chemical compounds including saponins, tannins, flavonoids, polyphenols, steroids. The purpose of this study was to determine the potential of red andong leaf extract (Cordyline fruticosa (L.) A. Cheval) as a radical scavenging antioxidant for DPPH. In this study red andong leaves (Cordyline fruticosa (L.) A. Cheval) were extracted using maceration method with $70 \%$ ethanol as solvent. The results showed that anthocyanins were cyanidin. Antioxidant activity was measured by reducing DPPH free radicals with UV-Vis spectrophotometry at a wavelength of $517 \mathrm{~nm}$. The results showed that red andong red leaf extract had strong antioxidant potential with an IC50 value of $64.5197 \mathrm{~g} / \mathrm{mL}$ against free radicals DPPH and vitamin C as a comparison showed a very strong antioxidant potential with an IC50 value of $2.12 \mathrm{~g} / \mathrm{mL}$.
\end{abstract}

Keywords : Andong leaf, antioxidant, DPPH

\begin{abstract}
Abstrak
Daun andong merupakan salah satu tanaman obat tradisional yang terbukti memiliki berbagai khasiat diantaranya sebagai bahan obat (alami). Tanaman andong mengandung beberapa senyawa kimia diantaranya yaitu saponin, tanin, flavonoid, polifenol, Steroida. Tujuan dari penelitian ini adalah untuk mengetahui potensi ekstrak daun andong merah (Cordyline fruticosa (L.) A. Cheval) sebagai antioksidan penangkal radikal DPPH. Pada penelitian ini daun andong merah (Cordyline fruticosa (L.) A. Cheval) diekstraksi dengan menggunakan metode maserasi dengan pelarut etanol $70 \%$. Hasil penelitian menunjukkan antosianin jenis sianidin. Aktivitas antioksidan diukur melalui peredaman radikal bebas DPPH dengan spektrofotometri UV-Vis pada panjang gelombang $517 \mathrm{~nm}$. Hasil Penelitian menunjukkan ekstrak daun andong merah memiliki potensi antioksidan kuat dengan nilai $\mathrm{IC}_{50} 64.5197 \mu \mathrm{g} / \mathrm{mL}$ terhadap radikal bebas DPPH dan vitamin $\mathrm{C}$ sebagai pembanding menunjukkan potensi antioksidan sangat kuat dengan nilai $\mathrm{IC}_{50}$ $2.12 \mu \mathrm{g} / \mathrm{mL}$.
\end{abstract}

Kata Kunci : Daun andong merah, antioksidan, DPPH

\section{PENDAHULUAN}

Radikal bebas merupakan atom atau senyawa yang mengandung satu atau lebih elektron yang tidak berpasangan. Senyawa paling berbahaya dalam radikal bebas yaitu hidroksil $(\mathrm{OH})$ sebab memiliki reaktivitas paling tinggi. Molekul tersebut sangat reaktif dalam mencari pasangan elektronnya. Jika sudah terbentuk dalam tubuh, maka akan terjadi reaksi berantai dan menghasilkan radikal bebas baru yang akhirnya membentuk suatu radikal bebas dalam jumlah yang banyak. Radikal bebas secara umum timbul akibat berbagai proses biokimiawi dalam tubuh, berupa hasil samping dari proses oksidasi yang berlangsung pada saat bernafas, metabolisme sel, olahraga yang berlebihan, peradangan, atau saat tubuh terpapar polusi lingkungan seperti asap kendaraan, asap rokok, bahan pencemar dan radiasi matahari ( Low dkk, 2007).
Seiring perkembangan zaman sudah banyak digunakan tanaman herbal/tradisional sebagai penangkal radikal bebas, Pada Daun andong merah digunakan sebagai obat diare dan disentri. Daun segar atau bunga kering digunakan dengan cara direbus dengan tiga gelas air sampai air gelas rebusan tersisa satu gelas, setelah dingin, disaring dan dibagi tiga sama banyak, diminum pada pagi, siang dan malam hari. Tanaman andong memiliki daun berwarna merah sehingga berpotensi dimanfaatkan sebagai zat warna atau pigmen alami (Susanto,2014). Kandungan kimia yang mengandung pada daun andong merah yaitu flavonoid, tannin, dan polifenol (Setiawan dalimartha.2006). Antosianin merupakan zat warna yang berperan memberikan warna merah secara alami untuk bahan pangan dan dapat dijadikan alternative pengganti warna sintesis 
yang lebih aman bagi kesehatan (Citramukti,2008).

Pada penelitian ini menguji aktivitas antioksidan akar sambiloto dengan menggunakan metode DPPH (1,1-Difenil-2-pikrilhidrazil). Metode DPPH memberikan informasi reaktivitas senyawa yang diuji dengan suatu radikal stabil. DPPH memberikan serapan kuat pada panjang gelombang $517 \mathrm{~nm}$ dengan warna ungu gelap . Berdasarkan uraian diatas, maka penulis tertarik untuk melakukan penelitian lebih lanjut mengenai potensi ekstrak etanol daun andong merah sebagai antioksidan penangkal radikal DPPH.. Hasil penelitian diharapkan dapat menjadi sumber informasi dalam penggunaan daun andong merah sebagai antioksidan.

\section{METODE PENELITIAN}

Alat-alat yang digunakan yaitu : alat gelas (Pyrex®), aluminium foil, incubator (MEMMERT $®)$, labu ukur (Pyrex®), neraca analitik (Mettler Toledo®), tabung reaksi (Pyrex®), pipet tetes, spektrofotometer Visibel ( SHIMADZU®), dan vial.

Bahan yang di gunakan adalah aquadest, asam sitrat, daun andong merah,aquadest, asam klorida $(\mathrm{HCl})$ pekat,etanol $70 \%$, etanol p.a, $\mathrm{FeCl}_{3}$ $1 \%$, natrium asetat $\left(\mathrm{CH}_{3} \mathrm{CO}_{2} \mathrm{Na} \cdot 3 \mathrm{H}_{2} \mathrm{O}\right)$, kalium klorida $(\mathrm{KCl})$, natrium hidroksida $(\mathrm{NaOH})$, serbuk $\mathrm{Mg}$, pereaksi Dragendrof, pereaksi Meyer, pereaksi Wagner, vitamin C

\section{Penyiapan Simplisia}

Pengambilan sampel daun andong merah (Cordyline fruticosa (L.) A. Cheval) di Daerah Kabupaten Bone Sulawesi Selatan.

Dilakukan pengambilan bahan baku kemudian dilakukan sortasi basah dan dicuci bersih dengan air mengalir. Selanjutnya dirajang, lalu dikeringkan dengan menggunakan oven pada suhu $50^{\circ} \mathrm{C}$ selama $2 \times 24$ jam untuk mengurangi kadar air. Kemudian ditimbang dan diremas, Selanjutnya dilakukan ekstraksi.

\section{Pembuatan Ekstrak}

Sampel Daun andong merah sebanyak 500 gram dibasahi dengan pelarut etanol $70 \%$, kemudian dimaserasi dengan pelarut etanol $70 \%$ sebanyak $3,750 \mathrm{~mL}$ selama $3 \times 24$ jam dan diaduk sesekali. Setelah didiamkan, kemudian disaring dan filtratnya ditampung. Kemudian dilakukan remaserasi kembali dengan menggunakan pelarut yang sama hingga jernih. Filtrat hasil maserasi dan remaserasi dicampur dan diuapkan,hingga memperoleh ekstrak kental.

\section{Uji Fitokimia \\ Identifikasi Alkaloid}

Ditimbang ekstrak 1 gram, dilarutkan dengan pelarut etanol $70 \%$, dipipet sebanyak 2 $\mathrm{mL}$ dimasukkan kedalam tabung reaksi, ditetesi dengan $\mathrm{HCl} 2 \mathrm{~N}$, lalu dibagi dalam 3 tabung reaksi. Tiap tabung ditambahkan dengan masingmasing pereaksi.Pada penambahan peraksi Mayer, positif mengandung alkaloid jika membentuk endapan putih.Pada penambahan pereaksi Wagner, positif mengandung alkaloid jika terbentuk endapan cokelat.Pada penambahan pereaksi Dragendroff, positif mengandung alkaloid terbentuk endapan jingga (Kusumawati, dkk, 2003).

\section{Identifikasi Flavanoid}

Ditimbang ekstrak 1 gram, dilarutkan dengan pelarut etanol $70 \%$, dipipet sebanyak 2 $\mathrm{mL}$ dimasukkan kedalam tabung reaksi, ditambahkan serbuk magnesium 0,1 gram dan 3 tetes $\mathrm{HCl}$ pekat. Apabila terbentuk warna jingga sampai merah menunjukkan adalanya flavon, merah sampai merah padam menunjukkan flavanol, merah padam sampai merah keunguan menunjukkan flavanon (Kusumawati, dkk, 2003).

\section{Identifikasi Saponin}

Ditimbang ekstrak 1 gram, dilarutkan dengan pelarut etanol $70 \%$, dipipet sebanyak 2 $\mathrm{mL}$ dimasukkan kedalam tabung reaksi ditambahkan $10 \mathrm{~mL}$ air panas, dinginkan kemudian kocok kuat-kuat selama 10 detik. Positif mengandung saponin jika terbentuk busa setinggi $1-10 \mathrm{~cm}$ selama tidak kurang dari 10 menit dan pada penambahan 1 tetes $\mathrm{HCl} 2 \mathrm{~N}$, busa tidak hilang (Depkes RI, 1995).

\section{Identifikasi Triterpenoid}

Ditimbang ekstrak 1 gram, dilarutkan dengan pelarut etanol $70 \%$, dipipet sebanyak 2 $\mathrm{mL}$ dimasukkan kedalam tabung reaksi ditambahkan $2 \mathrm{~mL}$ etanol 70\% kemudian dikocok, ditambahkan $1 \mathrm{~mL}$ kloroform dan $1 \mathrm{~mL}$ asetat anhidrida lalu dikeringkan. Setelah kering ditambahkan $\mathrm{H}_{2} \mathrm{SO}_{4}$. Apabila terbentuk warna kemerahan berarti positif mengandung triterpenoid (Mandal dan Ghasal, 2012).

\section{Identifikasi Tanin}

Ditimbang ekstrak 1 gram, dilarutkan dengan pelarut etanol $70 \%$, dipipet sebanyak 2 $\mathrm{mL}$ dimasukkan kedalam tabung reaksi kemudian dikocok dengan air panas hingga homogen setelah itu ditambahkan $\mathrm{FeCl}_{3}$, jika menghasilkan biru 
karakteristik biru-hitam, berarti mengandung tannin pirogalol. Sedangkan untuk tannin katekol dianggap positif jika ada penambahan larutan $\mathrm{FeCl}_{3}$ maka akan berwarna hijau atau biru-hijau dan endapan (Kusumawati, dkk, 2003).

\section{Uji pendahuluan antosianin dari ekstrak daun andong merah \\ Uji warna dengan $\mathrm{HCl}$}

Ekstrak daun andong merah sebanyak 50 mg di tambahkan $\mathrm{HCl} 2 \mathrm{M}$, kemudian dipanasakan $100^{\circ} \mathrm{C}$ selama 5 menit (+) merah.

Uji warna dengan $\mathrm{NaOH}$

Ekstrak daun andong merah sebanyak 50 mg ditambahkan $\mathrm{NaOH} 2 \mathrm{M}$ tetes demitetes sambil di amati perubahan warna yang terjadi (+) hijau biru memudar perlahan-lahan.

\section{Uji aktivitas antioksidan}

\section{Pembuatan Larutan DPPH}

Ditimbang DPPH sebanyak 7,9 mg kemudian di larutkan menggunakan pelarut etanol p.a sambil dihomogenkan. Pada volume akhir dicukupkan dengan etanol p.a sampai $50 \mathrm{ml}$ dalam labu tentukur

\section{Pembuatan Larutan}

Ekstrak daun andong merah dibuatkan Larutan stok 1000 ppm disiapkan dengan cara ditimbang masing-masing $50 \mathrm{mg}$ ekstrak daun andong merah dan di larutkan dengan etanol p.a sambil dihomogenkan, volume akhir di cukupkan dengan etanol p.a sampai $50 \mathrm{ml}$ dalam labu ukur.

\section{Pengukuran Aktivitas Antioksidan}

Pengujian aktivitas antioksidan dilakukan dengan metode DPPH. Dibuat 5 seri kosentrasi 1000 ppm dengan rentang $10 \mathrm{ppm}, 20 \mathrm{ppm}, 40 \mathrm{ppm}, 80 \mathrm{ppm}$, dan $100 \mathrm{ppm}$ dari larutan stok ekstrak, selanjutnya masing-masing dibuatkan seri kosentrasi ditambahkan $1 \mathrm{ml}$ larutan DPPH 0,4 $\mathrm{mM}$ dan dicukupkan volumenya hingga $5 \mathrm{ml}$ dengan etanol p.a campuran diinkubasi selama 30 menit pada suhu ruang dan diukur absorbansinya pada spektrofotometer visible dengan panjang gelombang $517 \mathrm{~nm}$.

\section{Pembuatan Larutan Pembanding Vitamin C}

Larutan stok 1000 ppm disiapkan dengan cara ditimbang $50 \mathrm{mg}$ vitamin $\mathrm{C}$ dan dilarutkan dengan etanol p.a sambil dihomogenkan, volume dicukupkan pada labu tentukur hingga $50 \mathrm{~mL}$. vitamin C 1000 bpj diencerkan ke dalam 10 ppm dengan cara dipipet $0,1 \mathrm{~mL}$ dan dicukupkan dengan etanol p.a sebanyak $10 \mathrm{~mL}$.

\section{Pengukuran Aktivitas Antioksidan Vitamin C}

Pengujian dilakukan memipet $1 \mathrm{~mL}$ larutan vitamin $C$ dari seri kosentrasi 1 ppm, 1,5 ppm, 2 ppm, 2,5 ppm, 3 ppm. Kemudian masing-masing ditambahkan $1 \mathrm{~mL}$ DPPH, dicukupkan volumenya dengan etanol p.a hingga $5 \mathrm{~mL}$, kemudian diinkubasi pada suhu $37^{\circ} \mathrm{C}$ diukur absorbansinya pada panjang gelombang $517 \mathrm{~nm}$. Dilakukan replikasi 3 kali untuk tiap konsentrasi sampel.

Presentasi inhibisi yaitu presentasi yang menunjukkan aktivitas radikal tersebut, presentasi inhibisi terhadap radikal DPPH dari masingmasing konsentrasi larutan sampel dapat dihitung dengan rumus :

\section{$\frac{\text { Absorban blanko-absorban sampel }}{\text { absorban blangko }} \times 100 \%$}

Setelah didapatkan presentase inhibisi dari masing-masing konsentrasi sampel dan persen inhibisi yang didapat diplotkan masing-masing pada sumbu $x$ dan y dalam persamaan regresi linear $y=a+b x$. Persamaan tersebut digunakan untuk menentukan nilai $\mathrm{IC}_{50}$ dari masing-masing sampel (16).

\section{HASIL DAN PEMBAHASAN}

Sampel yang digunakan dalam penelitian ini adalah daun andong merah (Cordyline frutycosa (L.) A. Cheval). Secara tradisional daun andong merah dimanfaatkan sebagai bahan obat (alami), berkhasiat untuk mengobati radang gusi, diare atau disentri, luka berdarah, wasir berdarah, pendarahan (haemostatik). Secara empiris, daun andong merah digunakan sebagai obat diare dan disentri (Dalimartha, 2006).

Sampel daun andong merah diperoleh dari Kabupaten Bone Provinsi Sulawesi Selatan. Selanjutnya di ekstraksi dengan menggunakan metode maserasi. Metode maserasi dipilih karena faktor kerusakan zat aktif lebih kecil. Metode ini tidak menggunakan panas yang dapat merusak zat aktif yang ditarik. Penekanan utama dalam metode ini adalah tersedianya waktu kontak yang cukup antara pelarut dengan jaringan yang terekstraksi. Maserasi dilakukan dengan cara merendam serbuk simplisia dalam cairan penyari (pelarut). Pelarut akan menembus dinding sel dan masuk kedalam rongga sel yang menggandung zat aktif (Hanum, 2000).

Pada metode ini sampel di rendam menggunakan pelarut etanol $70 \%$. Etanol dipilih karena mudah didapat serta merupakan pelarut polar yang dapat melarutkan senyawa aktif atau 
senyawa metabolit sekunder yang terdapat di dalam daun andong merah. Berat simplisia dari daun andong merah $500 \mathrm{mg}$, setelah mengalami pengelolahan dan diuapkan didapatkan berat ekstrak 17,07 gram hasil dari maserasi didapatkan ekstrak kental dengan perhitungan persen rendamen sebesar $3,414 \%$.

Tabel 1. Skrining Fitokimia Ekstrak Daun Andong Merah

\begin{tabular}{|c|c|c|c|}
\hline $\begin{array}{c}\text { Golongan } \\
\text { Senyawa } \\
\text { Kimia }\end{array}$ & $\begin{array}{c}\text { Hasil } \\
\text { Pengamatan }\end{array}$ & Literatur & $\begin{array}{c}\text { Kete } \\
\text { rang } \\
\text { an }\end{array}$ \\
\hline $\begin{array}{l}\begin{array}{l}\text { Alkaloid } \\
\text { (mayer) }\end{array} \\
\text { (wagner) } \\
\text { (dragendrof) }\end{array}$ & $\begin{array}{l}\text { Tidak Terjadi } \\
\text { pemisahan } \\
\text { Tidak Terjadi } \\
\text { pemisahan } \\
\text { Tidak Terjadi } \\
\text { pemisahan }\end{array}$ & $\begin{array}{l}\text { Endapan } \\
\text { putih } \\
\text { Endapan } \\
\text { coklat } \\
\text { Endapan } \\
\text { jingga }\end{array}$ & $\begin{array}{l}(-) \\
(-) \\
(-)\end{array}$ \\
\hline Flavanoid & $\begin{array}{l}\text { Berwarna } \\
\text { Merah }\end{array}$ & $\begin{array}{l}\text { Merah, } \\
\text { jingga dan } \\
\text { kuning }\end{array}$ & $(+)$ \\
\hline Triterpenoid & $\begin{array}{l}\text { Berwarna } \\
\text { merah }\end{array}$ & $\begin{array}{l}\text { Biru-hjau } \\
\text { (steroid) } \\
\text { Merah-ungu } \\
\text { (triterpenoid }\end{array}$ & $(+)$ \\
\hline Saponin & $\begin{array}{l}\text { Terbentuk } \\
\text { Buih }\end{array}$ & $\begin{array}{l}\text { Terbentuk } \\
\text { buih }\end{array}$ & $(+)$ \\
\hline Tanin & $\begin{array}{l}\text { Hijau } \\
\text { kehitaman }\end{array}$ & $\begin{array}{l}\text { Hijau } \\
\text { kehitaman }\end{array}$ & $(+)$ \\
\hline
\end{tabular}

Ket : Positif (+), Negatif (-)

Hasil skrining fitokimia dari ekstrak daun andong merah dengan pelarut etanol $70 \%$ dapat dilihat bahwa pada pengujian alkaloid yaitu mayer, wagner, dandragendrof menunjukkan hasil negatif. Pada pengujian flavanoid, triterpenoid, saponin, dan tanin, menunjukkan hasil positif.

Tabel 2. Uji pendahuluan antosianin dari ekstrak daun andong merah

\begin{tabular}{|c|c|c|}
\hline \multirow{2}{*}{ pengujian } & \multicolumn{2}{|c|}{ Hasil } \\
\cline { 2 - 3 } & $\begin{array}{c}\text { Hasil } \\
\text { Penelitian }\end{array}$ & $\begin{array}{c}\text { Menurut } \\
\text { Harbone } \\
\text { (1987) }\end{array}$ \\
\hline $\begin{array}{c}\text { Sampel + HCL } \\
\text { 2 M dan } \\
\text { dipanasakan } \\
\text { selama 5 menit } \\
\text { pada suhu 100 }{ }^{\circ}\end{array}$ & $\begin{array}{c}\text { Warna tetap } \\
\text { merah }\end{array}$ & $\begin{array}{c}\text { Warna tetap } \\
\text { merah }\end{array}$ \\
\hline $\begin{array}{c}\text { Sampel } \\
\text { ditambahkan } \\
\text { larutan NaOH 2 } \\
\text { M tetes demi } \\
\text { tetes. }\end{array}$ & $\begin{array}{c}\text { Warna } \\
\text { berubah } \\
\text { mendadi hijau } \\
\text { dan memudar } \\
\text { perlahan-lahan }\end{array}$ & $\begin{array}{c}\text { Warna } \\
\text { berubah } \\
\text { menjadi hijau } \\
\text { biru dan } \\
\text { memudar } \\
\text { perlahan- }\end{array}$ \\
\hline
\end{tabular}

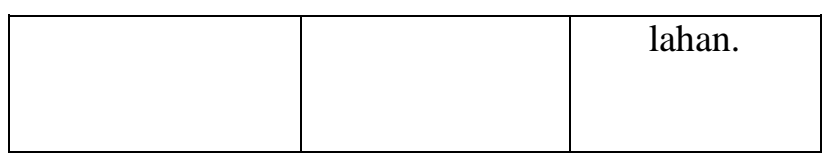

Uji pendahuluan antosianin dilakukan untuk mengidentifikasi senyawa antosianin berupa uji warna dengan cara ditimbang ekstrak kental daun andong merah sebanyak $50 \mathrm{mg}$ kemudian ditambahkan $\mathrm{HCl} 2 \mathrm{M}$. setelah ditambahkan dengan $\mathrm{HCl} 2 \mathrm{M}$, lalu dipanaskan dengan suhu $100^{\circ} \mathrm{C}$ selama 5 menit dan hasil yang didapatkan ekstrak daun andong merah tidak berubah warna, kemudian dilakukan lagi dengan cara ekstrak ditambahkan $\mathrm{NaOH} 2 \mathrm{M}$ tetes demi tetes hingga berubah warna dari hijau mudah memudar perlahan-lahan. Hal ini sesuai dengan penelitian yang dilakukan oleh Yulfriansyah dan Novitriani 2016 menyatakan bahwa penambahan $\mathrm{HCl} 2 \mathrm{M}$ menghasilkan warna merah, sedangkan pada penambahan $\mathrm{NaOH} 2 \mathrm{M}$ tetes demi tetes menghasilkan perubahan warna menjadi hijau kekuningan dan memudar perlahan lahan. Jenis antosianin dari ekstrak daun andong merah setelah penambahan $\mathrm{HCl} 2 \mathrm{M}$ dan $\mathrm{NaOH} 2 \mathrm{M}$ yaitu sianidin. Menurut jurnal Le Bellec 2006 dan Rifka Hardiyanti 2018 menyatakan bahwa pada penambahan $\mathrm{HCl} 2 \mathrm{M}$ memeberikan warna merah dan $\mathrm{NaOH} 2 \mathrm{M}$ memberikan warna hijau biru memudar perlahan-lahan. Secara kimia antosianin merupakan turunan struktur aromatik tunggal, yaitu sianidin, dan semuanya terbentuk dari pigmen sianidin dengan penambahan atau pengurangan gugus hidroksil, metilasi dan glikosilasi (Harborne, 1987).

\section{Pengujian Aktivitas Antioksidan Ekstrak daun Andong Merah}

Pengujian antioksidan ekstrak etanol daun andong merah serta larutan pembanding yaitu vitamin C. Dilakukan kosentrasi 1 ppm, dari larutan induk ekstrak menggunakan metode DPPH yang selanjutnya absorbansinya diukur menggunakan spektrovotometer UV-Vis.

Prinsip pengukuran aktivitas antioksidan dengan menggunakan metode DPPH adalah senyawa antioksidan akan mendonorkan atom hidrogennya pada radikal DPPH, sehingga menyebabkan DPPH menjadi bentuk tereduksi yang bersifat nonradikal. DPPH dalam bentuk nonradikal akan kehilangan warna ungu. Pudarnya warna ini ditandai pula dengan penurunan absorbansi DPPH pada panjang gelombang maksimum yang diukur menggunakan spektrofotometer UV-Vis (Kumalaningsih sri, 2006).

Pengujian aktivitas antioksidan ekstrak etanol akar sambiloto dengan menggunakan DPPH. 
Prinsip dari uji adalah adanya donasi atom hydrogen dari substansi yang diujikan pada radikal DPPH menjadi senyawa non radikal difenil pikril hidrazil yang ditandai dengan adanya perubahan warna. Perubahan warna yang akan terjadi adalah perubahan warna dari larutan berwarna ungu menjadi warna kuning (Molyneux, 2004). Selain itu, pengerjaannya juga mudah, cepat dan sensitif untuk menguji aktivitas antioksidan dari ekstrak tanaman menggunakan DPPH secara spektrofotometer (Pourmorad, F., et.al.,2006) dan metode ini hanya digunakan untuk menguji senyawa-senyawa antioksidan yang larut dalam pelarut organik khususnya alkohol ((Molyneux, 2004).

Dari nilai absorbansi DPPH yang diperoleh dapat ditentukan nilai persentasi penghambatan radikal DPPH (\% inhibisi). Pada nilai \% inhibisi dapat ditentukan nilai $\mathrm{IC}_{50}$ (inhibitory concentration). Nilai $\mathrm{IC}_{50}$ didefinisikan sebagai besarnya konsentrasi senyawa uji yang dapat meredam radikal bebas sebanyak 50\% yang dapat diperoleh dari persamaan regresi linier. Semakin kecil nilai $\mathrm{IC}_{50}$ maka aktivitas peredaman radikal bebas semakin tinggi (Molyneux, 2004).

Tabel 3. Nilai IC $_{50}$ Ekstrak etanol daun andong merah

\begin{tabular}{|c|c|c|c|c|c|c|}
\hline Kosentrasi & Replikasi & $\mathbf{A}$ & $\begin{array}{c}\text { Rata-rata } \\
\text { penghambata } \\
\mathbf{n}\end{array}$ & $\begin{array}{c}\% \\
\text { inhibisi }\end{array}$ & Nilai $\mathrm{IC}_{50}$ & Kategori \\
\hline Blanko & - & 0.847 & - & - & - & - \\
\hline \multirow{3}{*}{20} & 1 & 0.73 & \multirow{3}{*}{0.740333} & \multirow{3}{*}{$\begin{array}{c}12.5934 \\
7 \%\end{array}$} & \multirow{15}{*}{$\begin{array}{c}64.5197 \mu \mathrm{g} / \mathrm{m} \\
\mathrm{L}\end{array}$} & \multirow{15}{*}{ Kuat } \\
\hline & 2 & 0.74 & & & & \\
\hline & 3 & 0.751 & & & & \\
\hline \multirow{3}{*}{40} & 1 & 0.574 & \multirow{3}{*}{0.577333} & \multirow{3}{*}{$\begin{array}{c}31.8378 \\
6 \%\end{array}$} & & \\
\hline & 2 & 0.576 & & & & \\
\hline & 3 & 0.582 & & & & \\
\hline \multirow{3}{*}{60} & 1 & 0.393 & \multirow{3}{*}{0.391333} & \multirow{3}{*}{$\begin{array}{c}53.7977 \\
2 \%\end{array}$} & & \\
\hline & 2 & 0.391 & & & & \\
\hline & 3 & 0.39 & & & & \\
\hline \multirow{3}{*}{80} & 1 & 0.333 & \multirow{3}{*}{0.333333} & \multirow{3}{*}{$\begin{array}{c}60.6454 \\
2 \%\end{array}$} & & \\
\hline & 2 & 0.336 & & & & \\
\hline & 3 & 0.331 & & & & \\
\hline \multirow{3}{*}{100} & 1 & 0.22 & \multirow{3}{*}{0.220333} & \multirow{3}{*}{$\begin{array}{c}73.9866 \\
2 \%\end{array}$} & & \\
\hline & 2 & 0.221 & & & & \\
\hline & 3 & 0.22 & & & & \\
\hline Blanko & - & 0.847 & - & - & - & - \\
\hline
\end{tabular}

Tabel 4. Nilai $\mathrm{IC}_{50}$ Vitamin $\mathrm{C}$

\begin{tabular}{|c|c|c|c|c|c|c|}
\hline Kosentrasi & Replikasi & $\mathbf{A}$ & $\begin{array}{c}\text { Rata-rata } \\
\text { penghambata } \\
\mathbf{n}\end{array}$ & $\%$ inhibisi & Nilai IC $_{50}$ & Kategori \\
\hline Blanko & & 0,847 & - & - & & \\
\hline \multirow{3}{*}{1} & 1 & 0,660 & \multirow{3}{*}{0,679} & \multirow{3}{*}{$18,55 \%$} & \multirow{13}{*}{2.12} & \multirow{13}{*}{$\begin{array}{c}\text { Sangat } \\
\text { kuat }\end{array}$} \\
\hline & 2 & 0,676 & & & & \\
\hline & 3 & 0,693 & & & & \\
\hline \multirow{3}{*}{1,5} & 1 & 0,543 & \multirow{3}{*}{0,557} & \multirow{3}{*}{$32,89 \%$} & & \\
\hline & 2 & 0,559 & & & & \\
\hline & 3 & 0,569 & & & & \\
\hline \multirow{3}{*}{2} & 1 & 0,460 & \multirow{3}{*}{0,472} & \multirow{3}{*}{$43,13 \%$} & & \\
\hline & 2 & 0,473 & & & & \\
\hline & 3 & 0,486 & & & & \\
\hline \multirow{3}{*}{2,5} & 1 & 0,350 & \multirow{3}{*}{0,376} & \multirow{3}{*}{$54,69 \%$} & & \\
\hline & 2 & 0,381 & & & & \\
\hline & 3 & 0,397 & & & & \\
\hline 3 & 1 & 0,291 & 0,301 & $63,73 \%$ & & \\
\hline
\end{tabular}




\begin{tabular}{|l|l|l|l|l|l|l|}
\hline & 2 & 0,301 & & & \\
\cline { 2 - 3 } & 3 & 0,312 & & & & \\
\hline
\end{tabular}

Nilai $\mathrm{IC}_{50}$ ekstrak etanol daun andong merah (Cordyline fruticosa (L.) A. Cheval) Pada tabel di atas terlihat bahwa nilai $\mathrm{IC}_{50}$ ekstrak daun andong merah didapatkan nilai $\mathrm{IC}_{50} 64.5197$ $\mu \mathrm{g} / \mathrm{mL}$, Hal ini menunjukkan bahwa senyawa yang diduga terdapat dalam ekstrak mampu meredam aktivitas senyawa radikal bebas dengan kuat. Sedangkan pada vitamin C sebagai pembanding memiliki aktivitas antioksidan sangat kuat yaitu nilai $\mathrm{IC}_{50} 2.12 \mu \mathrm{g} / \mathrm{mL}$. Sehingga senyawa yang diduga memiliki potensi sebagai antioksidan yaitu golongan flavonoid berupa antosianin. Senyawa antosianin yang merupakan salah satu turunanya yaitu flavanoid. Senyawa antosianin merupakan zat warna yang berperan memberikan warna merah secara alami untuk bahan pangan dan dapat dijadikan alternative pengganti warna sintesis yang lebih aman bagi kesehatan (Citramukti,2008).

\section{KESIMPULAN}

Ekstrak daun andong merah berpotensi sebagai antioksidan penangkal radikal DPPH dengan nilai $\mathrm{IC}_{50} 64.5197 \mu \mathrm{g} / \mathrm{mL}$ tergolong Antioksidan kuat.

\section{DAFTAR PUSTAKA}

Citramukti, I, 2008, "Ekstraksi dan Uji Kualitas Pigmen Antosianin Pada Kulit Buah Naga Merah (Hylocereus polyrhizus L) (Kajian Masa Simpan Buah dan Penggunaan Pelarut)", Universitas Muhammadiyah Malang, Malang

Ghosal, M \& Mandal, P. 2012. Phytochemical Screening and Antioxidant Activities Of Two Selected 'Bihi' Fruits Used As Vegetables In Darjeeling Himalaya. Interantional Journal Of Pharmacy And Pharmaceutical Sciences. ISSN : 0975-1491.4(2)

Harborne, J. B., 1987, Metode Fitokimia Penuntun Cara ModernMenganalisis Tumbuhan, Bandung, ITB.
Harborne, J.B., (1996). Phytochemical Methods: A Guide to Modern techniques of Plant, Chapman and Hal: London.

Kusumawati, I., Djatmiko, W., dan Rahman, A. Studiawan, H., Ekasari, W. 2003. Eksplorasi Keanekaragaman dan Kandungan Kimia Tanaman Obat di Hujan Tropis Gunung Arjuno. Jurnal Bahan Alam Indonesia, 2(3): 100-104

Kumalaningsih Sri, 2006. Antioksidan alamipenangkal radikal bebas, sumber, manfaat, cara penyediaan dan pengelolahan. Trubus Agrisarana. Surabaya.

Molyneux, P. 2004. The Use of Stable Free Radical Diphenylpicrylhydrazyl (DPPH) for Estimating Antioxidant Activity. Songklanarin J, Sci. Technol, 26 (2), 211-219.

Rahayu, Ayu. 2010. Pengaruh berbagai variasi suhu dan warna kemasan terhadap stabilitas antosianin kulit mangis (Garcinia Mangostana L.) skripsi. Fakultas pertanian. Universitas Sebelas Maret. Susanto, dkk. 2014. Sintesis pigmen alami daun tanaman andong (cordyline fruticosa L.) sebagai pewarna batik dan analisis sifat optiknya. Universitas Negeri Semarang: Semarang.

Timberlake, C.F. dan Bridle, P. 1980. Anthocyanins. Di dalam Development In Food Colours-1. Walford, $J(E d)$. 1980. Applied Science Published Ltd. New York.

Pokorni. 2001. Antioxidant in Food, Practical Application. New York: CRS Press.

Underwood, A.L dan R.A. Day, Jr., 1999, "Analisis Kimia Kuantitatif". Jakarta : Erlangga

Valle, G.D., Meireles, M.A.A.A., 2005, "Antocianinas en Uva (Vitis vinifera) y su Relacion con en Color", Revista de Fitotecnologia, 28(4) : 1221-122 